\title{
Concretos com cinza do bagaço da cana-de-açúcar: avaliação da durabilidade por meio de ensaios de carbonatação e abrasão
}

\author{
Concretes made with sugarcane bagasse ash: evaluation \\ of the durability for carbonation and abrasion tests
}

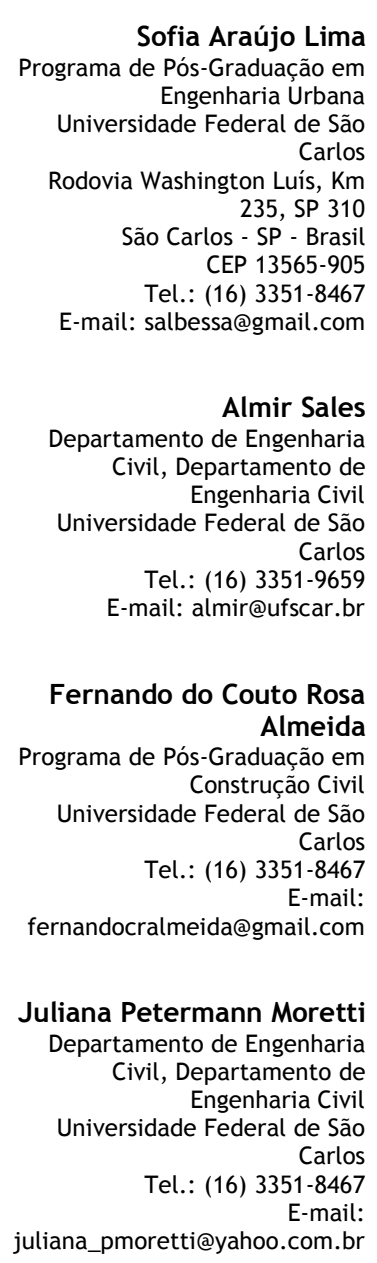

Sofia Araújo Lima

Programa de Pós-Graduação em Engenharia Urbana Universidade Federal de São Carlos

Rodovia Washington Luís, Km 235, SP 310 São Carlos - SP - Brasil CEP $13565-905$

Tel.: (16) $3351-8467$

E-mail: salbessa@gmail.com

$$
\begin{array}{r}
\text { Almir Sales } \\
\text { Departamento de Engenharia } \\
\text { Civil, Departamento de } \\
\text { Engenharia Civil } \\
\text { Universidade Federal de São } \\
\text { Carlos } \\
\text { Tel.: (16) 3351-9659 } \\
\text { E-mail: almir@ufscar.br }
\end{array}
$$

Fernando do Couto Rosa Almeida Programa de Pós-Graduação em Construçãao Civil Universidade Federal de São Carlos

Tel.: (16) 3351-8467 E-mail:

fernandocralmeida@gmail.com

Juliana Petermann Moretti Departamento de Engenharia

Civil, Departamento de Engenharia Civil Universidade Federal de São

Tel.: (16) 3351-8467 E-mail: juliana_pmoretti@yahoo.com.br

Kleber Franke Portella Departamento de Tecnologia em

Instituto de Tecnologia para o Desenvolvimento CP 19067

Curitiba - PR - Brasil CEP 81531-980

Tel.: (41) 3361-6220

E-mail: portella@lactec.org.br

Recebido em 20/10/10

Aceito em 26/04/11

\section{Sofia Araújo Lima \\ Almir Sales \\ Fernando do Couto Rosa Almeida \\ Juliana Petermann Moretti \\ Kleber Franke Portella}

\section{Resumo}

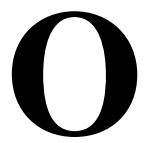

bagaço é gerado como resíduo do processamento do açúcar e do álcool. Esse resíduo é utilizado para a cogeração de energia por meio da queima em caldeiras, restando ao final as cinzas residuais do bagaço da cana-de-açúcar (CBC). Atualmente, essas cinzas são aproveitadas nas lavouras de cana como adubação orgânica, apesar de ser um material com poucos nutrientes. O objetivo deste trabalho foi avaliar a durabilidade de concretos que utilizaram a CBC em substituição ao agregado miúdo por meio de ensaios de carbonatação e abrasão. Os resultados foram comparados aos obtidos para um concreto sem CBC. Os concretos foram dosados para que tivessem a mesma consistência e o mesmo teor de argamassa.

Produziram-se traços com 0\%, 30\% e 50\% de CBC, em substituição ao agregado miúdo em três grupos diferentes. Foram realizados ensaios mecânicos e, a partir dos resultados obtidos, os concretos que apresentaram os melhores resultados foram submetidos ao ensaio de carbonatação, nas idades de 60, 120 e 210 dias, e ao ensaio de abrasão superficial, aos 28 dias. Os resultados obtidos permitiram concluir que a carbonatação e a abrasão do concreto produzido com a CBC como substituto parcial do agregado miúdo e o cimento CP II E 32 são similares ao concreto sem adição da cinza.

Palavras-chave: Concreto. Cinza do bagaço da cana-de-açúcar. Durabilidade.

\section{Abstract}

The bagasse is generated in the sugar and alcohol production process. This waste is used for cogeneration of electricity by burning it in boilers and at the end it produces sugarcane bagasse ash (SBA). Currently, those ashes are also used in cane plantations as organic fertilizer, despite the fact that it is poor in nutrients. The aim of this study was to evaluate the durability of concrete made with SBA as a replacement material for fine aggregate, through abrasion and carbonation tests. The results were compared to those obtained for a concrete without SBA. The concretes were designed to have the same workability and the same content of mortar. Mixes were made with $0 \%, 30 \%$ and $50 \%$ of SBA (in mass) replacing fine aggregate in three different groups. Mechanical tests were carried out with the concretes and the best concrete mixes made with SBA were submitted to the carbonation test at 60, 120 and 210 days, and the abrasion test at 28 days. The results indicated that the abrasion and carbonation of concrete produced with SBA as an aggregate replacement and slag-modified Portland cement are similar to concrete without ash addition.

Keywords: Concretes. Sugarcane bagasse ash. Durability. 


\section{Introdução}

O cultivo da cana-de-açúcar e a produção de seus derivados estão intimamente ligados à própria história e ao desenvolvimento do Brasil. Primeiramente transformada em açúcar, a cana-deaçúcar ocupa um importante papel na economia, tendo o Brasil como líder mundial na produção de açúcar e álcool. Porém, mesmo após séculos de convívio com a agroindústria canavieira, somente no século $\mathrm{XX}$, o Brasil descobriu no álcool uma opção energética viável.

\section{Cana-de-açúcar e seus resíduos}

De todos os resíduos da unidade industrial sucroalcooleira, o bagaço é um dos mais atrativos por causa de seu poder calorífico, o que faz dele a principal fonte energética do processo produtivo da fabricação do açúcar e do álcool (CORDEIRO et al., 2008; SOUZA et al., 2007).

Para cada tonelada de bagaço que alimenta o processo de cogeração são produzidos aproximadamente $25 \mathrm{~kg}$ de cinza residual. Atualmente, a destinação das cinzas do bagaço da cana-de-açúcar (CBC) é um dos problemas enfrentados pelos administradores das usinas. A fuligem gerada no processo é recolhida com técnicas de lavagem e decantação e, juntamente com a cinza de caldeira, constituem-se em resíduos finais do processo industrial, no qual não há possibilidade de redução deles (GANESAN; RAJAGOPAL; THANGAVEL, 2007; SOUZA et al., 2007).

As pesquisas nessa área apontam a necessidade de otimização do processo para a transformação desse resíduo em um material reativo ou pozolânico (GANESAN; RAJAGOPAL; THANGAVEL, 2007; FRÍAS; VILLAR; SAVASTANO, 2011). Essa mudança no processo das indústrias sucroalcooleiras pode significar um incremento de custos que dificulte a agregação de valor à CBC. A homogeneidade na produção das cinzas não pode ser exigida do processo industrial, que raramente possui controle operacional da temperatura de combustão e do resfriamento das cinzas (SALES; LIMA, 2010). Realizados dessa forma, sem controle, esses procedimentos tendem a produzir cinzas sem reatividade hidráulica.

As cinzas que não possuem reatividade podem ser usadas como material de carga inerte, em substituição aos agregados finos em matrizes cimentícias. A crescente elevação do custo da areia natural abre espaço para a entrada de outros materiais, como os resíduos, sendo esses de custo bem inferior aos correlatos naturais (SALES; LIMA, 2010). A CBC tem se mostrado um subproduto viável para aplicação em materiais de construção, desde que sejam observadas suas características intrínsecas, como o alto teor de sílica em forma de quartzo, um dos principais elementos presentes na areia natural (CORDEIRO et al., 2008).

\section{Durabilidade e as adições minerais}

Os critérios utilizados para avaliar a durabilidade do material podem levar em consideração os processos de deterioração. Esses processos estão associados a fenômenos físico-químicos que ocorrem entre os constituintes do concreto e os agentes agressivos, em geral presentes na água, tendo-se como exemplos o ingresso de cloretos e sulfatos, ciclos de molhagem-secagem, carbonatação, reação álcali-agregado, entre outros (MACEDO et al., 2009).

A carbonatação é um fenômeno que ocorre entre a portlandita (hidróxido de cálcio - $\mathrm{CH}$ ) e o $\mathrm{CO}_{2}$ presente no ar. Tal reação depende diretamente da umidade relativa do ar, da concentração de $\mathrm{CO}_{2}$, da pressão de penetração e da temperatura do meio ambiente (ATIS, 2003). O CH, no entanto, sofre carbonatação ao mesmo tempo em que o C-S-H (SILVA, 2007). Do ponto de vista físico, ocorre a deposição do carbonato nos poros, obturando-os e tamponando-os, o que diminui a continuidade dos poros ao longo do tempo. Assim, a própria carbonatação consiste em barreira eficaz contra si mesma, e a colmatação dos poros colabora com o aumento da dureza superficial do concreto, fato benéfico a concretos sujeitos a abrasão, além de, também, aumentar a proteção contra a ação de sulfatos (HELENE, 1995).

Por outro lado, a profundidade de carbonatação de concretos com adição de escória de alto forno e cinza volante pode ser até duas vezes maior do que a profundidade de carbonatação obtida em concretos sem adições. Esse fato pode estar relacionado à redução da alcalinidade advinda da redução da quantidade de cimento na mistura (XUEQUAN et al., 1999).

Outra pesquisa, no entanto, concluiu que, quanto maior a resistência à compressão, menor a porosidade e a profundidade de carbonatação de concretos com cinza volante, e que o aumento da porosidade resulta em aumento da profundidade de carbonatação para uma resistência à compressão constante, ou seja, a resistência mecânica não é o parâmetro único para o controle da carbonatação (ATIS, 2004).

A incorporação de adições minerais em concretos pode ter um efeito benéfico sobre algumas de suas 
propriedades, fato que pode ser explicado devido ao refinamento dos poros e dos grãos, aumento da tortuosidade dos canais e redução da interconectividade dos poros. A substituição parcial de areia por $\mathrm{CBC}$ aumentou a resistência à compressão de argamassas, aos 28 dias, para teores entre $20 \%$ e $30 \%$ (LIMA et al., 2009).

Nesse contexto, este trabalho teve como objetivo avaliar a durabilidade de concretos que utilizaram a CBC em substituição ao agregado miúdo por meio de ensaios de carbonatação e abrasão. Os valores obtidos nesses ensaios foram comparados aos obtidos para um concreto sem CBC. Esta avaliação também considerou as propriedades físicas e mecânicas que estão relacionadas à potencialidade do emprego desses concretos na produção de artefatos para infraestrutura urbana.

\section{Metodologia}

Para avaliar a durabilidade dos concretos produzidos com a $\mathrm{CBC}$, realizou-se, primeiramente, a caracterização dos materiais empregados. Os concretos, com teores de $30 \%$ e $50 \%$ de CBC em substituição ao agregado miúdo, foram submetidos a testes mecânicos que definiram os três melhores traços a serem analisados pelos ensaios de abrasão e carbonatação natural.

\section{Materiais}

$\mathrm{Na}$ composição dos concretos foram usados os seguintes materiais: cimento, areia (agregado miúdo), brita basáltica (agregado graúdo), cinza do bagaço da cana-de-açúcar (CBC) e água. A CBC foi coletada em usina de açúcar próximo à região de São Carlos, SP. Foram usados três tipos de cimento e, para cada um deles, determinou-se uma resistência de dosagem:

(a) CP V ARI RS (cimento Portland de alta resistência inicial resistente a sulfatos);

(b) CP III 40 RS (cimento Portland de alto forno resistente a sulfatos); e

(c) CP II E 32 (cimento Portland composto de alto forno).

As propriedades químicas e físicas dos cimentos utilizados estão apresentadas na Tabela 1.

A cinza do bagaço da cana-de-açúcar, utilizada nesta pesquisa, foi coletada em uma usina de açúcar e álcool distante $110 \mathrm{~km}$ da cidade de São Carlos, SP. As amostras utilizadas nas análises de caracterização e moldagem dos concretos foram obtidas a partir da CBC seca em estufa a $100{ }^{\circ} \mathrm{C}$, por $12 \mathrm{~h}$, e posteriormente moídas por $3 \mathrm{~min}$, na rotação de 65 RPM. O moinho utilizado foi o do tipo almofariz/pistilo motorizado, marca Marconi, modelo MA 590, cuba em cerâmica de alumina $\left(\mathrm{Al}_{2} \mathrm{O}_{3}\right.$ a $\left.96 \%\right)$, pistilo em cerâmica de alumina com diâmetro de $70 \mathrm{~mm}$ e $50 \mathrm{~mm}$ de altura. Esse tipo de moinho aceita amostras com diâmetro máximo de $30 \mathrm{~mm}$ e massa de até $200 \mathrm{~g}$ (Figura 1).

Tabela 1 - Propriedades químicas e físicas dos cimentos utilizados nos concretos

\begin{tabular}{lrrr}
\hline Componentes (\%) & CP V ARI RS & CP II E 32 & CP III 40 \\
\hline $\mathrm{SiO}_{2}$ & 19,65 & 21,41 & 26,06 \\
$\mathrm{Al}_{2} \mathrm{O}_{3}$ & 4,99 & 5,88 & 8,46 \\
$\mathrm{Fe}_{2} \mathrm{O}_{3}$ & 3,17 & 3,68 & 1,94 \\
$\mathrm{CaO}$ & 64,03 & 58,44 & 53,81 \\
$\mathrm{MgO}$ & 2,01 & 2,04 & 3,20 \\
$\mathrm{~K}_{2} \mathrm{O}$ & 0,69 & 0,73 & 0,50 \\
$\mathrm{CO}_{2}$ & 1,24 & 4,95 & 1,25 \\
$\mathrm{SO}_{3}$ & 2,33 & 1,26 & 2,42 \\
Perda ao fogo - $1.000{ }^{\circ} \mathrm{C}$ & 2,30 & 5,92 & 2,37 \\
Resíduo insolúvel & 0,50 & 1,72 & 0,38 \\
\hline Início de pega (min) & $\mathbf{1 6 7}$ & $\mathbf{1 8 4}$ & $\mathbf{1 9 1}$ \\
\hline Finura & & & \\
& & & \\
Material retido na \# 200 (\%) & 0,30 & 1,60 & 0,60 \\
$\mathrm{Blaine}\left(\mathrm{cm}{ }^{2} / \mathrm{g}\right.$ ) & 4.600 & 4.000 & 4.550 \\
\hline $\mathrm{Resistência} \mathrm{à} \mathrm{compressão} \mathrm{-} \mathrm{NBR} \mathrm{7215} \mathrm{(MPa)}$ & & \\
7 dias & 43,80 & 31,00 & 38,00 \\
28 dias & 52,00 & 40,00 & 48,00 \\
\hline
\end{tabular}

Fonte: Lima et al. (2009). 


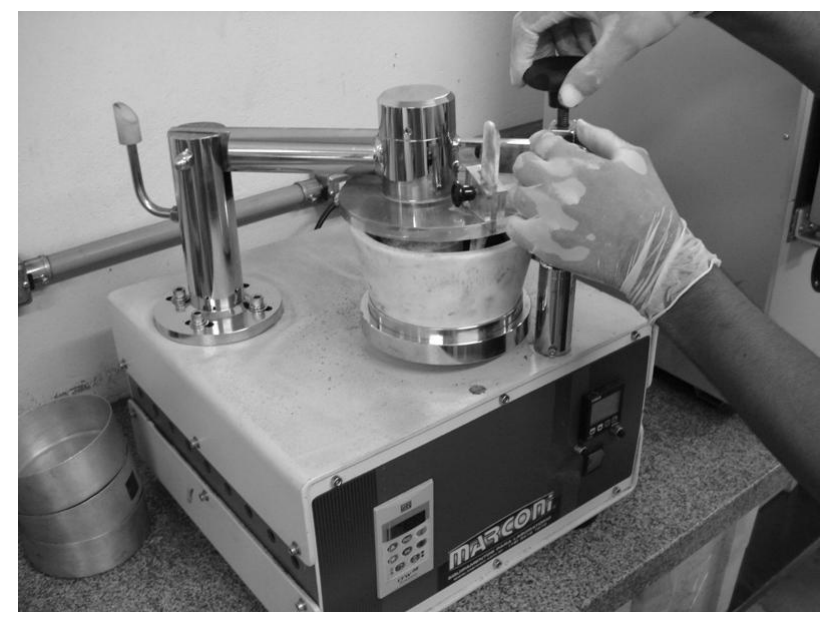

Figura 1 - Moagem da CBC em moinho do tipo almofariz-pistilo

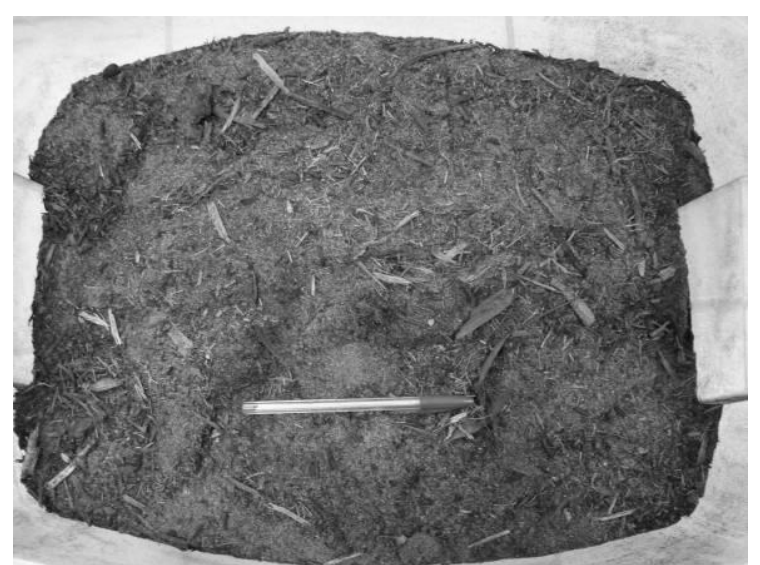

(a)

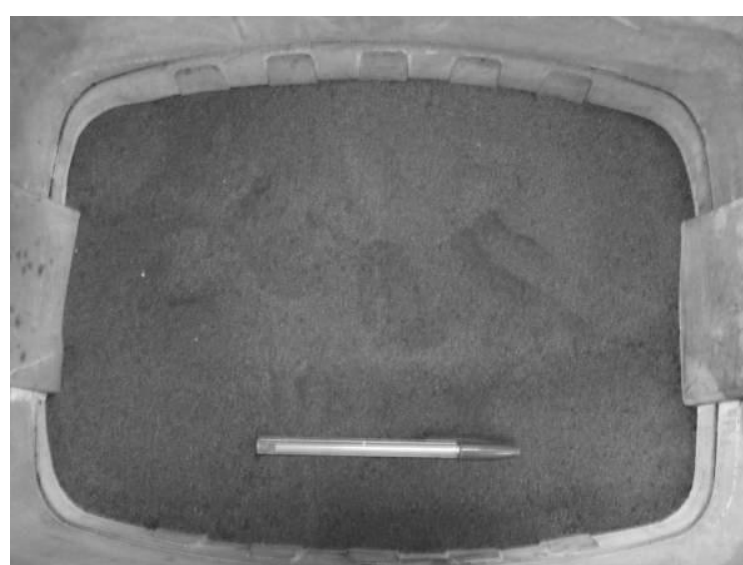

(b)

Figura 2 - (a) Aspecto da cinza não moída e (b) da cinza após a moagem

Tabela 2 - Análise química da cinza do bagaço da cana-de-açúcar

\begin{tabular}{ccccccccc}
\hline Elementos (\%) & $\mathbf{S i O}_{2}$ & $\mathbf{F e}_{2} \mathbf{O}_{\mathbf{3}}+\mathbf{A l}_{\mathbf{2}} \mathbf{O}_{\mathbf{3}}$ & $\mathbf{K}_{\mathbf{2}} \mathbf{O}+\mathbf{N a}_{2} \mathbf{O}$ & $\mathbf{C a O}$ & $\mathbf{P}_{2} \mathbf{O}_{5}$ & $\mathbf{M g O}$ & $\mathbf{S O}_{3}$ & Perda ao \\
\hline $\mathrm{CBC}$ & 96,2 & 1,9 & 0,3 & 0,1 & 0,1 & $<0,1$ & 0,1 & 1,04 \\
\hline
\end{tabular}

O material coletado nas usinas (in natura) apresentou granulometria correspondente a um material passante na peneira número 4 . O tempo de moagem foi estabelecido em função do tempo mínimo necessário para a homogeneização do material, uma vez que este apresentava pedaços de bagaço não queimados (Figura 2).

A caracterização das amostras de CBC, após a moagem, apresentou como resultados:

(a) massa específica no valor de $2,65 \mathrm{~kg} / \mathrm{dm}^{3}$;

(b) massa unitária no valor de $1,39 \mathrm{~kg} / \mathrm{dm}^{3}$;

(c) dimensão máxima característica no valor de $0,60 \mathrm{~mm}$; e

(d) módulo de finura no valor de 1,23.
Os valores da análise química da CBC estão apresentados na Tabela 2.

A caracterização do agregado miúdo apresentou os seguintes resultados: módulo de finura no valor de 2,10; dimensão máxima característica no valor de $2,40 \mathrm{~mm}$; massa específica no valor de $2,45 \mathrm{~kg} / \mathrm{dm}^{3}$; e massa unitária, no estado seco e solto, no valor de $2,04 \mathrm{~kg} / \mathrm{dm}^{3}$. O agregado graúdo apresentou os seguintes resultados: massa específica no valor de $2,63 \mathrm{~kg} / \mathrm{dm}^{3}$; massa unitária, no estado seco e solto, no valor de $0,98 \mathrm{~kg} / \mathrm{dm}^{3}$; e massa unitária compactada no valor de $1,58 \mathrm{~kg} / \mathrm{dm}^{3}$. As Tabelas 3 e 4 apresentam a análise granulométrica da areia e da brita respectivamente, segundo o método proposto pela NM 248 (ASOCIACIÓN..., 2003). 
Tabela 3 - Granulometria da areia natural

\begin{tabular}{cccc}
\hline \multirow{2}{*}{$\begin{array}{c}\text { Peneiras } \\
(\mathbf{m m})\end{array}$} & \multicolumn{3}{c}{ \% Retida Acumulada } \\
\cline { 2 - 4 } & Ensaio 1 & Ensaio 2 & Média \\
\hline 6,3 & 0,50 & 0,20 & 0,40 \\
4,8 & 0,80 & 0,90 & 0,80 \\
2,4 & 2,50 & 2,90 & 2,70 \\
1,2 & 14,40 & 15,30 & 14,80 \\
0,6 & 32,70 & 33,70 & 33,20 \\
0,3 & 68,60 & 68,30 & 68,40 \\
0,15 & 90,30 & 89,90 & 90,10 \\
uundo $^{(1)}$ & 99,90 & 100,00 & 99,90 \\
\hline $\mathrm{DMC}^{(2)}$ & $2,4 \mathrm{~mm}$ & $2,4 \mathrm{~mm}$ & $2,4 \mathrm{~mm}$ \\
$\mathrm{MF}^{(2)}$ & 2,10 & 2,11 & 2,10 \\
\hline
\end{tabular}

Tabela 4 - Análise granulométrica do agregado graúdo

\begin{tabular}{ccccc}
\hline \multirow{2}{*}{$\begin{array}{c}\text { Peneiras } \\
(\mathbf{m m})\end{array}$} & Ensaio 1 & Ensaio 2 & Ensaio 3 & Média \\
\cline { 2 - 5 } \% Retida Acumulada \\
25,5 & 0,0 & 0,0 & 0,0 & 0,0 \\
19,0 & 0,0 & 0,0 & 0,0 & 0,0 \\
12,5 & 0,0 & 0,0 & 0,0 & 0,0 \\
9,5 & 10,6 & 8,8 & 10,4 & 9,9 \\
6,3 & 57,0 & 51,7 & 56,5 & 55,1 \\
4,8 & 90,2 & 87,3 & 89,0 & 88,8 \\
fundo & 96,1 & 92,7 & 94,4 & 94,4 \\
\hline DMC $^{(1)}$ & 99,9 & 99,9 & 99,4 & 99,8 \\
MF $^{(2)}$ & $19 \mathrm{~mm}$ & $19 \mathrm{~mm}$ & $19 \mathrm{~mm}$ & $19 \mathrm{~mm}$ \\
\hline
\end{tabular}

Nota: ${ }^{(1)}$ DMC = Dimensão máxima característica $\left(D_{\text {máx }}\right)$ e ${ }^{(2)} M F=$ Módulo de finura.

A areia utilizada nesta pesquisa atendeu aos requisitos da NBR 7211 (ABNT, 2005) e pode ser classificada como areia fina (zona 2). No entanto, a brita não se enquadrou em nenhum dos limites granulométricos apresentados pela NBR 7211 e não pode ser classificada por tais parâmetros, ficando entre a graduação da brita 0 e da brita 1 . Todos os ensaios de caracterização dos agregados foram realizados no Laboratório de Materiais e Componentes da Universidade Federal de São Carlos, segundo a normalização brasileira.

\section{Análise mecânica dos concretos}

Para as análises com os concretos, determinaramse três traços, $0 \%, 30 \%$ e $50 \%$ de CBC, em substituição ao agregado miúdo. Esses teores de substituição foram determinados em uma etapa prévia de análises com argamassas (LIMA et al., 2009). Determinou-se uma resistência padrão $\left(f_{\mathrm{c} 28}\right)$ para cada grupo/tipo de cimento. A dosagem dos traços preliminares foi calculada segundo o método da Associação Brasileira de Cimento Portland (ABCP).

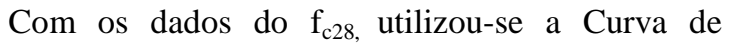
Abrams para determinar a relação água/cimento inicial dos traços de referência, denominados:

(a) AR (traço de referência com cimento do tipo CPV ARI RS);

(b) BR (traço de referência com cimento do tipo CPIII 40 RS); e

(c) CR (traço de referência com cimento do tipo CPII E 32).

Após os cálculos iniciais de dosagem, o parâmetro determinante para a adaptação e a uniformização dos traços iniciais em laboratório foi a consistência no estado fresco, mantida constante para todos os traços (abatimento $=70 \pm 10 \mathrm{~mm}$ ). Esses traços de referência foram submetidos a testes em laboratório para se determinar a consistência e 
efetuar ajustes na dosagem inicial. Os dados das dosagens obtidas são apresentados na Tabela 3.

As principais ações realizadas no estudo de dosagem, na tentativa de se uniformizar a consistência, foram feitas no teor de argamassa e no consumo de cimento. Essa uniformização foi necessária para que todos os concretos tivessem a mesma possibilidade de aplicação, ou seja, concretos de consistência entre plástica e fluida.

Após os ajustes em cada traço de referência (AR, BR e CR), os traços com a adição de CBC foram calculados e também testados em laboratório. O consumo de cimento ficou em $425 \mathrm{~kg} / \mathrm{m}^{3}$ para todos os concretos. O teor de argamassa também foi mantido constante, no valor de 51,30\%. Dessa forma, mesmo com as diferenças no tipo de cimento e na classe de resistência, foi possível uma comparação posterior sobre o desempenho mecânico de cada tipo de concreto. Os dados referentes às dosagens encontram-se na Tabela 5.

Para a análise das propriedades no estado endurecido, moldaram-se corpos de prova cilíndricos em formas de PVC (Ø $10 \mathrm{~cm}$ x $20 \mathrm{~cm})$, com adensamento do tipo mecânico utilizando vibrador de imersão do tipo agulha.

Após a moldagem, os corpos de prova permaneceram em seus moldes por $24 \mathrm{~h}$ e, depois desse período, foram desmoldados e acondicionados em câmara úmida (temperatura 23 $\pm 2^{\circ} \mathrm{C}$ e umidade relativa $95 \pm 5 \%$ ) até a idade de ensaio e/ou ruptura. Os ensaios desenvolvidos com os concretos, aos 28 dias, foram:

(a) resistência à compressão, de acordo com a NBR 5739 (ABNT, 1994);

(b) massa específica; índice de vazios; e

(c) absorção de água por imersão, segundo a NBR 9778 (ABNT, 1987).

\section{Análise da carbonatação dos concretos}

Após os resultados dos ensaios mecânicos com os concretos, foram escolhidos para o ensaio de carbonatação, entre os seis traços produzidos com a CBC em substituição parcial ao agregado miúdo, os três traços que obtiveram os melhores resultados (A50, C30 e C50), assim como seus respectivos traços de referência (AR e $\mathrm{CR}$ ).

Foram moldados três corpos de prova cilíndricos (Ø $10 \mathrm{~cm}$ x $20 \mathrm{~cm}$ ) para cada traço, que permaneceram em câmara úmida $(\mathrm{UR}=95 \pm 5 \%$ ) por 28 dias e depois em câmara seca de temperatura e umidade controladas $\left(\mathrm{T}=23 \pm 2{ }^{\circ} \mathrm{C} /\right.$ $\mathrm{UR}=60 \pm 5 \%$ ) até a data de ensaio. Os concretos foram ensaiados na idade de 60, 120 e 210 dias pelo método colorimétrico (RILEM, 1984). Esse método consiste em se tratar uma superfície recém-rompida com solução de fenolftaleína diluída em álcool. $\mathrm{O} \mathrm{CH}$ adquire uma tonalidade avermelhada (componente básico, $\mathrm{pH}>8,0$ ), enquanto a parte que sofreu carbonatação (componente ácido, $\mathrm{pH}<8,0$ ) permanece incolor.

De um modo geral, a fenolftaleína é o indicador de pH mais utilizado no meio científico devido à facilidade de uso, rapidez na realização do ensaio, custo baixo e precisão relativamente boa. Deve-se lembrar que a cor vermelha pode indicar a presença de $\mathrm{CH}$, mas não a ausência total de carbonatação. A frente de carbonatação não pode ser considerada rígida, mas gradual (VILLAIN; THIERY; PLATRET, 2007). Esse tipo de ensaio pode ser empregado como método comparativo e qualitativo entre amostras.

Essa comparação é feita pela medição, com paquímetro, da frente de carbonatação do corpo de prova rompido diametralmente, indicada pela ausência de cor após o tratamento com a solução de fenolftaleína.

Tabela 5 - Dosagens dos concretos obtidas em laboratório

\begin{tabular}{|c|c|c|c|c|c|c|c|c|}
\hline \multirow{2}{*}{$\begin{array}{l}\text { Tipo de } \\
\text { cimento }\end{array}$} & \multirow{2}{*}{$\begin{array}{c}\text { Resistência à } \\
\text { compressão }-\mathbf{f}_{28}\end{array}$} & \multirow{2}{*}{ Série } & \multirow{2}{*}{$\begin{array}{l}\text { Teor de } \\
\text { CBC }\end{array}$} & \multicolumn{5}{|c|}{ Composição do traço de concreto (em massa) } \\
\hline & & & & Cimento & Areia & Brita & CBC & Fator $\mathbf{a} / \mathbf{c}$ \\
\hline \multirow{3}{*}{$\begin{array}{l}\text { CPV ARI } \\
\text { RS }\end{array}$} & \multirow{3}{*}{$45 \mathrm{MPa}$} & AR & $0 \%$ & 1,00 & 1,830 & 2,690 & 0,000 & 0,52 \\
\hline & & $\mathrm{A} 30$ & $30 \%$ & 1,00 & 1,281 & 2,690 & 0,549 & 0,53 \\
\hline & & A50 & $50 \%$ & 1,00 & 0,915 & 2,690 & 0,915 & 0,54 \\
\hline \multirow{3}{*}{$\begin{array}{l}\text { CPIII } 40 \\
\text { RS }\end{array}$} & \multirow{3}{*}{$32 \mathrm{MPa}$} & BR & $0 \%$ & 1,00 & 2,120 & 2,860 & 0,000 & 0,53 \\
\hline & & B30 & $30 \%$ & 1,00 & 1,484 & 2,860 & 0,636 & 0,54 \\
\hline & & B50 & $50 \%$ & 1,00 & 1,060 & 2,860 & 1,060 & 0,55 \\
\hline \multirow{3}{*}{$\begin{array}{c}\text { CPII E } \\
32\end{array}$} & \multirow{3}{*}{$25 \mathrm{MPa}$} & $\mathrm{CR}$ & $0 \%$ & 1,00 & 2,010 & 2,860 & 0,000 & 0,52 \\
\hline & & $\mathrm{C} 30$ & $30 \%$ & 1,00 & 1,407 & 2,860 & 0,603 & 0,53 \\
\hline & & C50 & $50 \%$ & 1,00 & 1,005 & 2,860 & 1,005 & 0,54 \\
\hline
\end{tabular}




\section{Análise da abrasão dos concretos}

Para a análise de abrasão, foram moldados os três traços que obtiveram os melhores resultados nas análises mecânicas (A50, C30 e C50), assim como seus respectivos traços de referência (AR e CR). As amostras foram moldadas em formas específicas ( $\varnothing 30 \mathrm{~cm}$ x $10 \mathrm{~cm}$ altura), em acordo com a norma C 1138 (ASTM, 2005), no Laboratório de Materiais e Estruturas do LACTEC/UFPR (Figura 3).

Os corpos de prova permaneceram em câmara úmida (UR $=95 \pm 5 \%$ ) por 28 dias e depois foram submetidos ao ensaio de abrasão por 3 dias, com medições a cada $24 \mathrm{~h}$.

\section{Resultados e discussões}

Os resultados das análises das propriedades dos concretos estudados e as discussões estão apresentados a seguir.

\section{Avaliação de propriedades físicas e mecânicas}

Os resultados dos ensaios de resistência à compressão dos concretos, aos 28 dias, são apresentados na Tabela 6. O coeficiente de variação dos resultados individuais manteve-se abaixo de $6 \%$ para todas as séries, como recomenda a NBR 7215 (ABNT, 1996).

Para todas as séries avaliadas foi possível obter valores que permitem indicar uma distribuição do tipo normal para os valores obtidos nos ensaios de resistência à compressão dos concretos com e sem a adição da CBC. Os baixos valores obtidos para o desvio padrão das amostras e também o coeficiente de variação entre $0,76 \%$ e $5,03 \%$ atestam a pequena variabilidade dos ensaios realizados. Para as séries " $A$ " e " $B$ " os valores para a resistência à compressão são próximos aos valores obtidos para os respectivos concretos de referência, principalmente se forem considerados os valores dos desvios padrão obtidos. Para os concretos da série "C" foi possível verificar um aumento significativo do valor de resistência à compressão, mesmo com a consideração dos valores de desvios padrão para os concretos produzidos com adição de CBC e cimento do tipo CPII E 32.
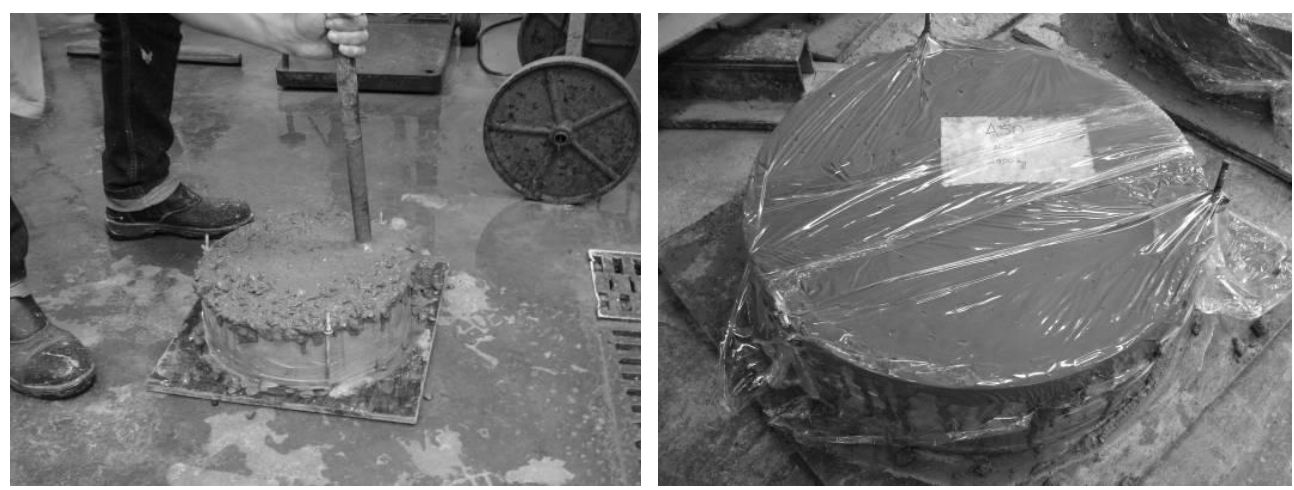

Figura 3 - Moldagem dos corpos de prova para o ensaio de abrasão

Tabela 6 - Valores de resistência à compressão dos concretos, aos 28 dias

\begin{tabular}{cccc}
\hline Série & $\begin{array}{c}\text { Resistência à compressão - } \\
\text { média simples (MPa) }\end{array}$ & Desvio padrão & $\begin{array}{c}\text { Coeficiente de } \\
\text { variação (\%) }\end{array}$ \\
\hline AR & 44,77 & 0,34 & 0,76 \\
A30 & 42,67 & 2,14 & 5,03 \\
A50 & 43,05 & 0,85 & 1,97 \\
\hline BR & 25,61 & 0,56 & 2,17 \\
B30 & 23,47 & 0,59 & 2,51 \\
B50 & 22,47 & 0,92 & 4,11 \\
\hline CR & 23,78 & 0,87 & 3,64 \\
C30 & 27,98 & 0,74 & 2,66 \\
C50 & 28,72 & 0,66 & 2,31 \\
\hline
\end{tabular}


Nas séries A e B os valores de referência foram maiores que os valores de resistência dos concretos com CBC, aos 28 dias. Para a série A, a diferença ficou em $3,80 \%$ entre o traço AR e o A50, e para a série $\mathrm{B}$, a diferença foi maior, tendo ficado em $12,22 \%$ entre o traço BR e o B50. Os exemplares do traço C50 apresentaram valor médio 17,20\% maior que as amostras de referência. $\mathrm{Na}$ série $\mathrm{C}$ todos os concretos produzidos com CBC apresentaram valores de resistência à compressão significativamente superiores aos do concreto referência - CR.

Os concretos da série $\mathrm{B}$, confeccionados com o CP III $40 \mathrm{RS}$, obtiveram os resultados menos expressivos por não ultrapassarem o valor de 25 MPa. Em função disso, no prosseguimento da experimentação para a avaliação da durabilidade, os concretos da série B foram desconsiderados.

Os ensaios de índice de vazios e absorção dos concretos foram realizados, segundo as recomendações da norma NBR 9778 (ABNT, 1987), nos concretos com idade de 28 dias. Os resultados estão apresentados na Tabela $7 . \mathrm{O}$ traço C30 apresentou o menor teor de vazios e também o menor valor de absorção entre todos os traços. Os traços da série B apresentaram os maiores índices de vazios em relação aos menores valores de resistência à compressão, o que reforçou a descontinuidade dos concretos da série $\mathrm{B}$ no prosseguimento da experimentação para a avaliação da durabilidade.

Os valores de massa específica para os concretos com adição de CBC variaram entre $2329 \mathrm{~kg} / \mathrm{m}^{3}$ para o concreto B50 (CPIII com 50\% CBC) e $2383 \mathrm{~kg} / \mathrm{m}^{3}$ para o concreto A30 (CP V com $30 \%$ de $\mathrm{CBC}$ ). O menor valor de ar incorporado foi encontrado nos concretos da amostra C30. Segundo Neville (1997), o volume total de vazios de dado volume de concreto interfere em sua resistência à compressão. $\mathrm{O}$ teor ótimo de ar incorporado para concretos moldados com agregado graúdo com dimensão máxima igual a $19 \mathrm{~mm}$ e condições severas de exposição é de $6 \%$ (AMERICAN..., 1977).

A partir dos resultados de resistência à compressão e teores de vazios, deu-se continuidade à análise dos concretos, com a verificação da profundidade de carbonatação natural e abrasão.

Sabe-se que, quanto menor a resistência à compressão, maior será o teor de vazios de um concreto e maior será sua frente de carbonatação, pois os poros podem facilitar a entrada de $\mathrm{CO}_{2}$ no material e, por consequência, desencadear a reação com seus componentes (ATIS, 2004). Desse modo, os concretos da série B foram desconsiderados para os ensaios subsequentes pelos maiores índices de vazios observados, além das menores resistências a compressão, comparando-se aos valores obtidos para o concreto de referência.

Os valores de massa específica para os concretos com adição de CBC variaram entre $2329 \mathrm{~kg} / \mathrm{m}^{3}$ para o concreto B50 (CPIII com 50\% CBC) e $2383 \mathrm{~kg} / \mathrm{m}^{3}$ para o concreto A30 (CP V com $30 \%$ de $\mathrm{CBC}$ ). O menor valor de ar incorporado foi encontrado nos concretos da amostra C30. Segundo Neville (1997), o volume total de vazios de dado volume de concreto interfere em sua resistência à compressão. $\mathrm{O}$ teor ótimo de ar incorporado para concretos moldados com agregado graúdo com dimensão máxima igual a 19 mm e condições severas de exposição é de $6 \%$ (AMERICAN..., 1977).

A partir dos resultados de resistência à compressão e teores de vazios, deu-se continuidade à análise dos concretos, com a verificação da profundidade de carbonatação natural e abrasão.

Tabela 7 - Valores dos ensaios de absorção, índice de vazios e massa específica no estado endurecido

\begin{tabular}{cccc}
\hline Traços & Absorção $(\%)$ & Índice de vazios $(\%)$ & Massa específica $\left(\mathbf{k g} / \mathbf{m}^{\mathbf{3}}\right)$ \\
\hline AR & 5,09 & 12,10 & 2378 \\
A30 & 5,06 & 12,06 & 2383 \\
A50 & 5,29 & 12,55 & 2374 \\
\hline BR & 6,85 & 15,93 & 2327 \\
B30 & 5,33 & 12,51 & 2349 \\
B50 & 5,96 & 13,87 & 2329 \\
\hline CR & 5,14 & 12,16 & 2366 \\
C30 & 5,01 & 11,92 & 2380 \\
C50 & 5,58 & 13,16 & 2356 \\
\hline
\end{tabular}

Nota: * valores em itálico: melhores resultados de cada série. 
Sabe-se que, quanto menor a resistência à compressão, maior será o teor de vazios de um concreto e maior será sua frente de carbonatação, pois os poros podem facilitar a entrada de $\mathrm{CO}_{2}$ no material e, por consequência, desencadear a reação com seus componentes (ATIS, 2004). Desse modo, os concretos da série $\mathrm{B}$ foram desconsiderados para os ensaios subsequentes pelos maiores índices de vazios observados, além das menores resistências a compressão, comparando-se aos valores obtidos para o concreto de referência.

\section{Avaliação de propriedades relacionadas à durabilidade}

No ensaio de carbonatação natural, os corpos de prova foram rompidos diametralmente na respectiva idade de ensaio, e as superfícies foram tratadas com a solução de fenolftaleína.

Os resultados da medição da frente de carbonatação dos concretos são apresentados nos gráficos da Figura 4. Os valores do coeficiente de variação dos resultados ficaram em torno de 15$20 \%$ para todos os concretos, nas três idades.
Todas as amostras confeccionadas com a CBC obtiveram valores de profundidade de carbonatação maiores que os respectivos concretos de referência, porém os valores de profundidade de carbonatação da amostra C30 e da amostra CR ficaram muito próximos dos valores do concreto de referência, na idade de 210 dias.

No caso dos concretos com CBC, a acidez das amostras de CBC pode ter influenciado a redução da alcalinidade do concreto, o que facilitou o avanço da frente de carbonatação. Análises de solubilização (NBR 10005:2004) e lixiviação (NBR 10006:2004) realizadas na amostra de CBC utilizada nos concretos apresentaram valores na ordem de 7,8 para o $\mathrm{pH}$ do solubilizado e de 4,96 para o pH do lixiviado (LIMA et al., 2009).

Em relação ao ensaio de desgaste superficial por abrasão, os resultados estão apresentados no gráfico da Figura 5. Os concretos confeccionados com o cimento $\mathrm{CP} \mathrm{V}$ tiveram, em média, desempenho superior aos concretos produzidos com o cimento composto CP II.

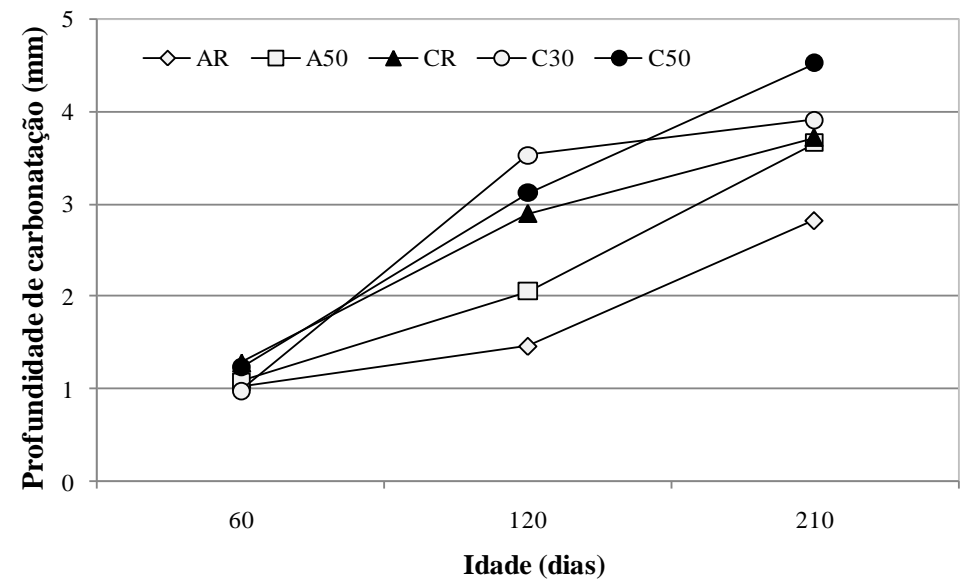

Figura 4 - Valores de profundidade de carbonatação dos concretos em estudo

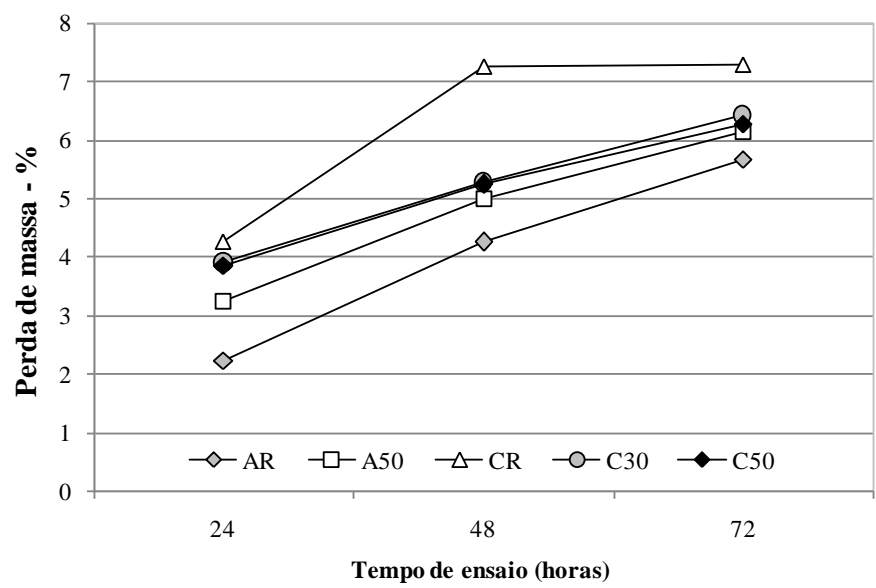

Figura 5 - Valores da perda de massa dos concretos por meio do ensaio de abrasão 

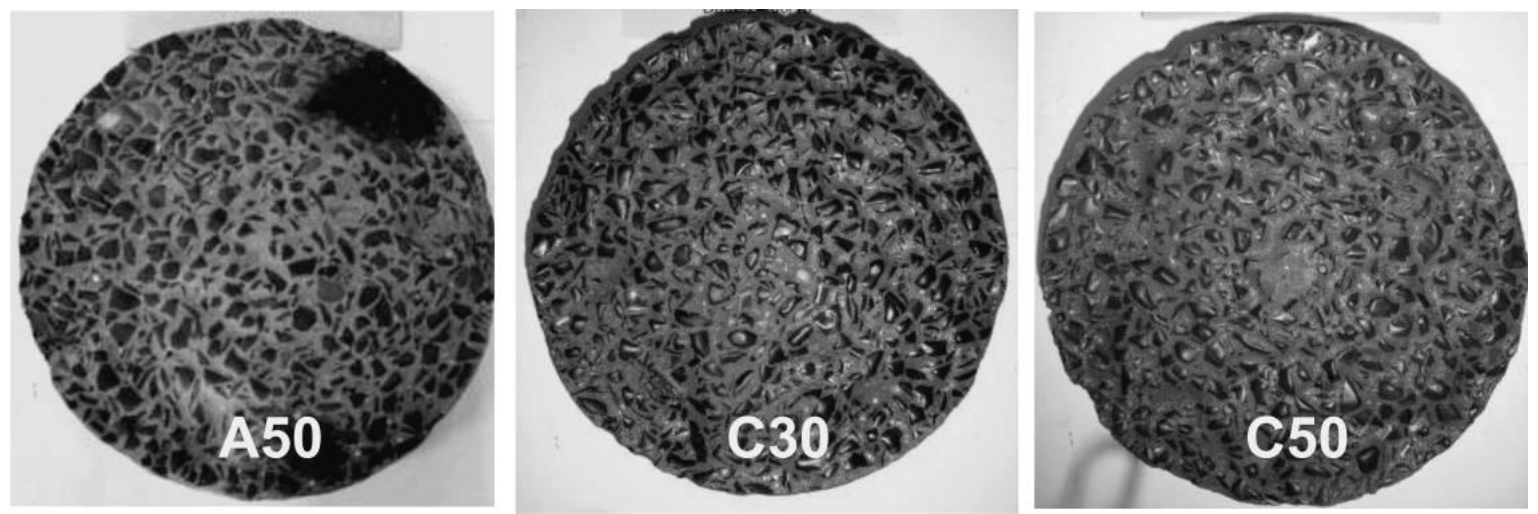

Figura 6 - Corpos de prova de concreto submetidos ao ensaio de abrasão, após 72 h

Após $72 \mathrm{~h}$ de ensaio as amostras confeccionadas com a CBC obtiveram valores médios de perda de massa muito próximos, entre $6,15 \%$ para o A50 e $6,42 \%$ para o C30. Esses valores podem ser considerados equivalentes entre si. Nota-se que o desgaste superficial foi semelhante ao desgaste observado nos concretos confeccionados com a CBC. Na Figura 6 pode ser observado o aspecto dos corpos de prova submetidos ao ensaio de abrasão, após 72 h. Observou-se o mesmo comportamento ao desgaste superficial tanto para os concretos de referência como para os concretos com CBC, ou seja, a resistência ao desgaste superficial aumentou com o incremento da resistência à compressão.

Siddique (2003) estudou concretos confeccionados com cinza volante (classe F) em substituição ao agregado miúdo e atestou que a resistência ao desgaste aumenta com o aumento da resistência à compressão.

\section{Conclusões}

Ao final das discussões realizadas, observou-se melhor desempenho, na série $\mathrm{A}$, do concreto de referência (AR) em relação ao concreto com a CBC. Na série $\mathrm{C}$ o concreto confeccionado com $50 \%$ de CBC obteve melhores valores de resistência à compressão e abrasão, apenas não superando o concreto de referência de sua série em relação à profundidade de carbonatação. Desse modo, pode-se concluir que:

(a) os concretos confeccionados com a CBC e cimento CP II E 32 (cimento composto) obtiveram valores de resistência à compressão maiores que os exemplares de referência;

(b) os concretos produzidos com $30 \%$ e $50 \%$ de CBC e o cimento CP II E 32 (série C) apresentaram o menor valor de índice de vazios e, também, o menor valor de absorção entre todos os traços estudados; (c) os concretos confeccionados com a CBC obtiveram valores de profundidade de carbonatação maiores que os valores de profundidade de carbonatação obtidos para os concretos de referência;

(d) o traço C30 obteve a menor profundidade de carbonatação entre os concretos confeccionados com a CBC, comparando-se com seu respectivo traço de referência; e

(e) o concreto produzido com 50\% de substituição de agregado miúdo por $\mathrm{CBC}$ obteve o melhor desempenho (menor desgaste superficial) entre os concretos que utilizaram o cimento do tipo CPII E 32 (série C).

Esses resultados indicam que os concretos com a $\mathrm{CBC}$ podem ser utilizados em estruturas aparentes de concreto armado com tratamento impermeabilizante da superfície, por terem maior propensão à carbonatação.

A cinza do bagaço da cana-de-açúcar pode ser utilizada como material substituto parcial do agregado miúdo (30\% a $50 \%$ de substituição) na produção de artefatos de concreto para infraestrutura urbana submetidos a ações abrasivas superficiais de intensidade leve.

\section{Referências}

\section{AMERICAN CONCRETE INSTITUTE. ACI}

211.1: recommended practice for selecting proportions for normal and heavy weight concrete. Detroit, 1977. 23 p.

\section{AMERICAN SOCIETY OF TESTING} MATERIALS. ASTM C 1138: concreto: determinação da resistência à abrasão de concreto (Standard test method for abrasion resistence of concrete - Underwater Method). West Conshohocken: ASTM, 2005. 
ASSOCIAÇÃO BRASILEIRA DE NORMAS TÉCNICAS. NBR 5739: concreto: ensaio de compressão de corpos-de-prova cilíndricos. Rio de Janeiro, 1994.

\section{ASSOCIAÇÃO BRASILEIRA DE NORMAS TÉCNICAS. NBR 7211: agregados para concretos. Rio de Janeiro, 2005.}

\section{ASSOCIAÇÃO BRASILEIRA DE NORMAS} TÉCNICAS. NBR 7215: cimento Portland: determinação da resistência à compressão. Rio de Janeiro, 1996.

ASSOCIAÇÃO BRASILEIRA DE NORMAS TÉCNICAS. NBR 9778: argamassa e concreto endurecido: determinação da absorção de água por imersão: índice de vazios e massa específica. Rio de Janeiro, 1987.

\section{ASSOCIAÇÃO BRASILEIRA DE NORMAS} TÉCNICAS. NBR 10005: procedimento para obtenção de extrato lixiviado de resíduos sólidos. Rio de Janeiro, 2004.

\section{ASSOCIAÇÃO BRASILEIRA DE NORMAS} TÉCNICAS. NBR 10006: procedimento para obtenção de extrato solubilizado de resíduos sólidos. Rio de Janeiro, 2004.

\section{ASOCIACIÓN MERCOSUR DE} NORMALIZACIÓN. NM 248: agregados: determinação da composição granulométrica. São Paulo, 2003.

ATIS, C. D. Accelerated Carbonation and Testing of Concrete Made With Fly Ash. Construction and Building Materials, v. 17, n. 3, p. 147-152, 2003.

ATIS, C. D. Carbonation-Porosity-Strength Model for Fly Ash Concrete (Technical Note). Journal of Materials in Civil Engineering, Technical Note, p. 91-94, jan./feb. 2004.

CORDEIRO, G. C. et al. Pozzolanic Activity and Filler Effect of Sugar Cane Bagasse Ash in Portland Cement and Lime Mortars. Cement and Concrete Composites, v. 30, n. 5, p. 410-418, 2008.

FRÍAS, M.; VILLAR, E.; SAVASTANO, H. Brazilian Sugar Cane Bagasse Ashes from the Cogeneration Industry as Active Pozzolans for Cement Manufacture. Cement and Concrete Composites, v. 33, n. 4, p. 490-496, apr. 2011.

GANESAN, K.; RAJAGOPAL, K.;

THANGAVEL, K. Evaluation of Bagasse Ash as a Supplementary Cementitious Material. Cement and Concrete Composities, v. 29, n. 6, p. 515524, 2007.

HELENE, P. R. L. Vida Útil das Estruturas. Téchne, n. 17, p. 28-31, jul./ago. 1995.
LIMA, S. A. et al. Análise de Argamassas Confeccionadas Com a Cinza do Bagaço da Canade-Açúcar em Substituição ao Agregado Miúdo. Revista Tecnológica, v. 18, p. 87-97, 2009.

MACEDO, P. C. et al. Revisão Bibliográfica Sobre o Uso de Cinza de Bagaço de Cana-deAçúcar na Construção Civil. In: CONGRESSO BRASILEIRO DO CONCRETO, 51., 2009, Curitiba. Anais... Curitiba: IBRACON, 2009.

NEVILLE, A. M. Propriedades do Concreto. São Paulo: PINI, 1997.

\section{RILEM CONCRETE PERMANENT} COMMITEE. RILEM Draft Recommendation: measurement of hardened concrete carbonation depth CPC-18. Materials and Structures, v. 17, n. 102 , p. 435-440, 1984.

SALES, A.; LIMA, S. A. Use of Brazilian Sugarcane Bagasse Ash in Concrete as Sand Replacement. Waste Management, v. 30, n. 6, p. 1114-1122, 2010.

SIDDIQUE, R. Effect of Fine Aggregate Replacement With Class F Fly Ash on the Abrasion Resistance of Concrete. Cement and Concrete Research, v. 33, n. 11, p. 1877-1881, 2003.

SILVA, V. M. Ação da Carbonatação em Vigas de Concreto Armado em Serviço, Construídas em Escala Natural e Reduzida. São Carlos, 2007. Tese (Doutorado em Engenharia Civil) - Escola de Engenharia de São Carlos, Universidade de São Paulo, São Carlos, 2007.

SOUZA, G. N. et al. Denvolvimento de Argamassas com Substituição Parcial do Cimento Portland por Cinzas Residuais do Bagaço de Canade-Açúcar. In: CONGRESSO BRASILEIRO DO CONCRETO, 49., 2007, Bento Gonçalves. Anais... São Paulo: IBRACON, 2007.

VILLAIN, G.; THIERY, M.; PLATRET, G. Measurement Methods of Carbonation Profiles in Concrete: thermogravimetry, chemical analysis and gammadensimetry. Cement and Concrete Research, v. 37, n. 8, p. 1182-1192, 2007.

XUEQUAN, W. et al. Study on Steel Slag and Fly Ash Composite Portland Cement. Cement and Concrete Research, v. 29, n. 7, p. 1103-1106, 1999.

\section{Agradecimentos}

À Fundação de Amparo à Pesquisa do Estado de São Paulo (FAPESP), à Coordenação de Aperfeiçoamento de Pessoal de Nível Superior (CAPES) e ao Conselho Nacional de Desenvolvimento Científico e Tecnológico (MCT/CNPq). 
Revista Ambiente Construído

Associação Nacional de Tecnologia do Ambiente Construído

Av. Osvaldo Aranha, $99-3^{\circ}$ andar, Centro

Porto Alegre - RS - Brasil

CEP $90035-190$

Telefone: +55 (51) 3308-4084

Fax: +55 (51) 3308-4054

www.seer.ufrgs.br/ambienteconstruido

E-mail: ambienteconstruido@ufrgs.br

212 Lima, S. A.; Sales, A.; Almeida, F. do C. R.; Moretti, J. P.; Portella, K. F. 